
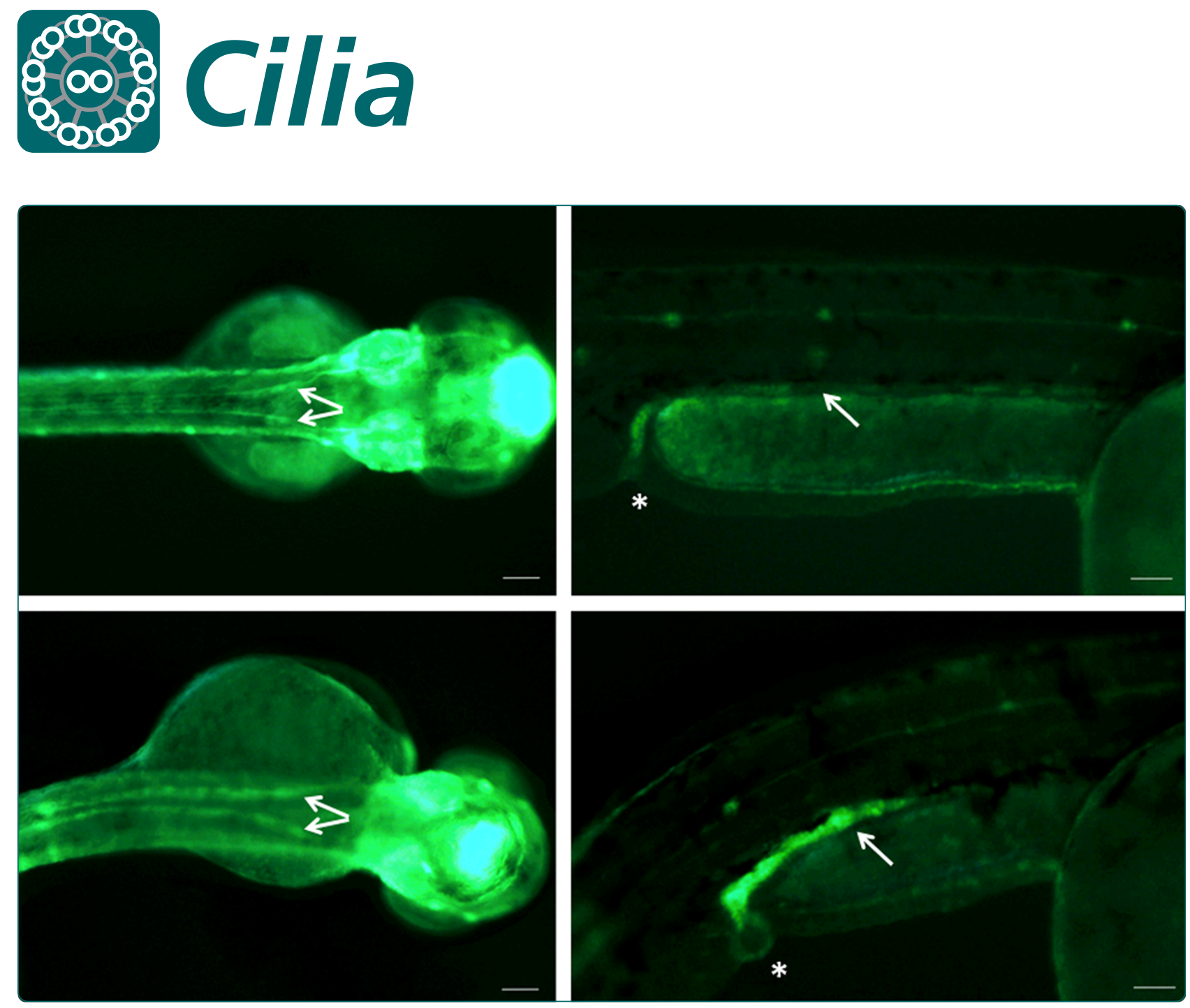

\title{
Functional modelling of a novel mutation in BBS5
}

Al-Hamed et al. 


\title{
Functional modelling of a novel mutation in BBS5
}

\author{
Mohamed H Al-Hamed ${ }^{1,2}$, Charles van Lennep ${ }^{1}$, Ann Marie Hynes ${ }^{1}$, Paul Chrystal ${ }^{1}$, Lorraine Eley', \\ Fatimah Al-Fadhly ${ }^{3}$, Riham El Sayed ${ }^{4}$, Roslyn J Simms ${ }^{1}$, Brian Meyer ${ }^{2}$ and John A Sayer ${ }^{1 *}$
}

\begin{abstract}
Background: Bardet-Biedl syndrome (BBS) is an autosomal recessive ciliopathy disorder with 18 known causative genes (BBS1-18). The primary clinical features are renal abnormalities, rod-cone dystrophy, post-axial polydactyly, learning difficulties, obesity and male hypogonadism.

Results: We describe the clinical phenotype in three Saudi siblings in whom we have identified a novel mutation in exon 12 of BBS5 (c.966dupT; p.Ala323CysfsX57). This single nucleotide duplication creates a frame shift results in a predicted elongated peptide. Translation blocking Morpholino oligonucleotides were used to create zebrafish bbs 5 morphants. Morphants displayed retinal layering defects, abnormal cardiac looping and dilated, cystic pronephric ducts with reduced cilia expression. Morphants also displayed significantly reduced dextran clearance via the pronephros compared to wildtype embryos, suggesting reduced renal function in morphants. The eye, kidney and heart defects reported in morphant zebrafish resemble the human phenotype of BBS5 mutations. The pathogenicity of the novel BBS5 mutation was determined. Mutant mRNA was unable to rescue pleiotropic phenotypes of bbs 5 morphant zebrafish and in cell culture we demonstrate a mislocalisation of mutant BBS5 protein which fails to localise discretely with the basal body.
\end{abstract}

Conclusions: We conclude that this novel BBS5 mutation has a deleterious function that accounts for the multisystem ciliopathy phenotype seen in affected human patients.

Keywords: BBS, Zebrafish, Pronephros, Cilia, Situs inversus, Retinopathy

\section{Background}

BBS is a rare autosomal recessive disorder [1] which is now considered, given its pleiotropic and multisystem features and the known function of BBS proteins, to be a ciliopathy. The incidence of BBS, has been reported to be 1 in 125,000 in the UK [1] and 1 in 160,000 in Switzerland [2]. It is more common in some small populations such as Newfoundland (1 in 18,000) [3] and the Bedouin community of Kuwait ( 1 in 13,500) [4] where there may be a founder effect [5] and an increased incidence of consanguineous relationships [6].

Following a comprehensive analysis of known BBS patients in the UK, Beales et al. provided revised diagnostic criteria for the clinical syndrome. Currently, four out of six primary features of BBS or three out of six primary features and at least two of eleven secondary features are required for a clinical diagnosis [7] The primary features

\footnotetext{
* Correspondence: john.sayer@ncl.ac.uk

${ }^{1}$ International Centre for Life, Institute of Genetic Medicine, Newcastle University, Central Parkway, Newcastle NE1 3BZ, UK

Full list of author information is available at the end of the article
}

include renal abnormalities (renal cystic dysplasia and anatomical malformations), rod-cone dystrophy, postaxial polydactyly, learning difficulties, truncal obesity and male hypogonadism [7]. The renal manifestations of BBS are the most life-limiting component of the disorder $[8,9]$. Out of the 11 secondary features, four (brachydactyly, developmental delay, speech deficit and higharched palate) have been reported to affect over $40 \%$ of BBS patients [7]. There is considerable variation in the phenotypes of affected individuals, even between affected siblings [10]. Additional phenotypes have also been reported in BBS patients, including cardiac malformations [11], situs inversus [12] and anosmia [13].

BBS is a genetically heterogeneous disorder with mutations in 18 known genes (BBS1-18) [14-16] accounting for approximately $80 \%$ of patients with BBS. In 2004, Li et al. identified BBS5 using an elegant comparative genomics method [17]. Comprehensive bioinformatics carried out on BBS5 by Nachury et al. discovered that two novel domains in the BBS5 protein were similar to pleckstrin homology $(\mathrm{PH})$ domains which bind to phosphoinositides [18]. 
Phosphoinositides are phosphorylated forms of phosphatidylinositol that are found in cell membranes and have functional links with RABs including Rab8 [19]. BBS5 isolates bind to phosphoinositides in vitro and because both siRNA inhibition of BBS5 and inhibition of phosphoinositides resulted in loss of ciliation [18], this suggests that BBS5 binding to phosphoinositides is needed for ciliogenesis [18].

We report an interesting novel BBS5 mutation in a consanguineous family from Saudi Arabia. Given that this mutation was not a missense or nonsense mutation but led to a predicted elongated transcript that may retain functional activity, we sought to characterise this mutation further. The pathogenicity of this novel mutation was assessed in a zebrafish model, where it was unable to rescue pleiotropic phenotypes of $b b s 5$ knockdown and in cell culture assays, where the novel mutation led to BBS5 mutant protein mislocalisation in renal epithelial cells (Qiagen, Manchester, UK).

\section{Methods}

\section{Study cohort}

This study has been approved by the research advisory council of King Faisal Specialist Hospital, Riyadh, Saudi Arabia (RAC\#2050 045). Following informed consent, DNA was extracted from peripheral blood cells using the Gentra Systems Puregene DNA Isolation kit (Qiagen, Manchester, UK).

\section{Homozygosity mapping and mutation analysis}

To search for homozygous regions and possible chromosomal abnormalities, all available family members were genotyped with an Affymetrix ${ }^{\odot}$ CytoScan $^{\mathrm{Tm}}$ Array. The primary data was analysed using Chromosome Analysis Suite (ChAS) software (Affymetrix). Direct sequencing of all coding exons and exon-intron boundaries of BBS5 was performed. Primer sequences are available upon request. PCR products were sequenced using BigDye ${ }^{\mathrm{Ts}}$ Terminator Cycle Sequencing kit (PE Applied Biosystems, Bedford, MA, USA). Sequences were analysed using Mutation Surveyor ${ }^{\circledR}$ software Version 3.24 (SoftGenetics LLC, State College, PA 16803, USA). Mutations were labelled according to the Human Genome Variation Society (HGVS) recommendations version 2.0. A control DNA panel from 96 individuals from a Saudi Arabian population was used to screen for the novel sequence variant.

\section{Zebrafish studies}

For zebrafish studies, all procedures were performed under Home Office UK license regulations. Transgenic fluorescent reporter fish were used for studying cardiac morphology ( $c m l c 2$ :GFP, the GFP gene under the control of the cardiac myosin light chain 2 gene promoter [20]) and renal morphology (cldnb:lynGFP, a membranelocalised variant of the GFP gene under the control of the claudin $b$ gene promoter [21]). Other zebrafish lines used were wildtype (WT) AB and golden. Zygotes were collected from natural spawning and placed in petri dishes of E3 medium ( $5 \mathrm{mM} \mathrm{NaCl}, 0.17 \mathrm{mM} \mathrm{KCl}, 0.33 \mathrm{mM}$ $\mathrm{CaCl}_{2}, 0.33 \mathrm{mM} \mathrm{MgSO}_{4}$ ) [22].

Morpholino oliogonucleotides (MOs) were manufactured by Gene Tools LLC (Philomath, OR, USA). The standard control (5' -CCTCTTACCTCAGTTACAATTTATA-3') and p53 translation targeting (5'-GCGCCATTGCTTTG CAAGAATTG-3') MO sequences were of pre-established design. MO sequences for bbs5 translation targeting (ATG) (5'-GATCACTGTCTGCGTATATTGTCGA-3') were designed with reference to the zebrafish genome assembly Zv9.

Stock MOs in RNase free water were diluted with $0.05 \%$ phenol red in Danieau buffer to produce the solution for injection. Dilutions of 3 to $12 \mathrm{ng}$ of MO per $2 \mathrm{nl}$ of solution were used. All MOs, except the p53 ATG MO, were used individually. The $p 53$ ATG MO was coinjected in a 1:1 mixture with the bbs5 ATG MO in order to assess any p53-mediated off-target effects [23] of the bbs5 ATG MO. MOs were microinjected under light microscopy into the yolk of one- to four-cell embryos, using a glass micropipette and an Eppendorf FemtoJet pneumatic micro-injector. The micropipettes were calibrated by measuring droplet size on a reticle so that $2 \mathrm{nl}$ of $\mathrm{MO}$ solution were injected into each embryo. After microinjection, the embryos were placed in fresh E3 medium, approximately 50 embryos per petri dish, and incubated at $28.5^{\circ} \mathrm{C}$. Mortality counts were performed at 3 and 24 hours post fertilisation (hpf) on both injected and uninjected control embryos. Clutches where the mortality rate in uninjected embryos was above $50 \%$ at $24 \mathrm{hpf}$ were discarded.

Human BBS5 EST clone (BC044593.1) inserted into vector pBluescriptR was obtained (GeneService) and the clone was sequenced to verify clone length and fidelity. To obtain mutant BBS5 (c.966dupT), site directed mutagenesis was employed. Using a T7 forward oligonucleotide primer and reverse oligonucleotide primer within the 3' UTR of BBS5, PCR products of 1,194 bp were obtained and used as a template to perform an in vitro synthesis of large cRNA (mMessage mMachine T7 kit (Ambion, Inc., AM1340)). cRNA samples were purified by phenol:chloroform extraction and isopropanol precipitation.

cRNA was mixed 1:1 with bbs5 ATG MO in its microinjection solution to achieve $100 \mathrm{pg}$ of mRNA and $5 \mathrm{ng}$ of $\mathrm{MO}$ in $2 \mathrm{nl}$ of the final solution. This solution was then microinjected into one- to four-cell embryos as described. Western blotting was used to confirm WT BBS5-NT-GFP and c.966dupT mutant BBS5-NT-GFP protein expression. Briefly, protein was extracted using an extraction buffer (4 M urea, $125 \mathrm{mM}$ Tris $\mathrm{pH}$ 6.8, $4 \%$ SDS, $10 \%$ glycerol, 5\% beta-mercaptoethanol, and $0.02 \%$ bromophenol blue). Samples were separated using 
SDS-polyacrylamide gel electrophoresis and then electrophoretically transferred to Hybond-C-extra nitrocellulose membranes (Fisher Scientific UK Ltd). Protein was detected using an anti GFP-HRP (Santa Cruz sc-9996, Santa Cruz Biotechnologies Inc., Santa Cruz, CA, USA) (1 in 5,000 dilution) for one hour at room temperature before developing and imaging.

\section{Zebrafish phenotypic data}

Light and fluorescent microscopy was performed to monitor the embryos at 24, 48 and $72 \mathrm{hpf}$. Embryos were dechorinated (using forceps) and immobilised in $0.1 \%$ tricaine in E3. The phenotypes of each fish at 72 hpf were recorded, noting the presence of pericardial effusion, tail length and appearance, body oedema and venous stasis in the cardiac venous sinus. Pronephric duct morphology assessment in cldnb:lynGFP fish was performed at $48 \mathrm{hpf}$ and $72 \mathrm{hpf}$. For ciliary staining, embryos were fixed in acetone and stained with mouse acetylated tubulin antibody (Sigma, UK), secondarily detected with Alexa Fluor 594 (Invitrogen Life Sciences Ltd.). To assess cardiac morphology (D-loop, L-loop or failure of looping and cardiac chamber appearance), 72 hpf $c m l c 2$ :GFP embryos were used.

Fish were classed phenotypically as i) normal if they were indistinguishable from uninjected fish; ii) mildly affected if they had small eyes, mild pericardial effusion and mild/no tail defects; iii) moderately affected if they had a large pericardial effusion and moderate tail defects (obvious shortening and large kinks/curls in their tails). Fish exhibiting a very severe or 'monster phenotype' [24] (no or very short malformed tail, widespread oedema, malformed eyes and minimal cardiac muscle contraction) were noted but not used in the analysis of morphology [24]. Eye size was measured using superior view photograph using the long axis length of each zebrafish eye. Images were taken with a Leica DF425C camera and the Leica Application Suite V3 program and analysis was performed using ImageJ Software (National Institutes of Health).

\section{Histological analysis of zebrafish morphants}

Seventy-two hpf control and bbs5 ATG MO injected (mild to moderate phenotype) embryos were euthanised in $4 \%$ tricaine and fixed in $2 \%$ glutaraldehyde in $0.1 \mathrm{M}$ cacodylate buffer for two hours at room temperature. They were then dehydrated in a stepwise manner in acetone then impregnated with epoxy resin in stepwise fashion. Embryos in 100\% epoxy resin were then placed individually in coffin moulds (EMS \#70905-01) and polymerised at $60^{\circ} \mathrm{C}$ for 24 hours. One micrometer transverse microtome sections were stained with $1 \%$ toluidine blue in $1 \%$ borax. In parallel, zebrafish were also embedded in (Electron Microscopy Sciences, Hatfield, PA, USA) and allowed to set in a low humidity environment.
A glass knife was used to cut $5 \mu \mathrm{m}$ sections which were then stained by Lee's trichrome and mounted in Histamount. Sections were then analysed on a Zeiss Axioplan 2 light microscope and images were taken (Zeiss AxioCam HRc camera).

\section{Renal function studies in zebrafish embryos and morphants}

Uninjected control embryos and bbs5 ATG MO injected embryos with a mild to moderate phenotype were selected at $48 \mathrm{hpf}$ and dechorinated and immobilised using 0.1\% tricaine in E3. Four nanograms of $10 \mathrm{kDa}$ tetramethylrhodamine dextran (dissolved in RNase free water) were microinjected into the cardiac venous sinus, lateral and inferior to the heart. To confirm successful cardiac injection, embryos were checked for the presence of fluorescence within the heart under fluorescent microscopy. A lateral view fluorescent image of each fish was taken at 3, 24 and 48 hours post dextran injection keeping exposure, saturation, gamma, gain and zoom level were all constant. A $100 \times 100$ pixel square from the centre of the heart for each fish was taken and the average intensity measured using ImageJ software. Pronephric ducts and cilia were visualised using a Nikon A1R confocal microscope and Elements software package.

\section{Cell culture and transfection}

Routine tissue culture techniques were used to facilitate the growth of the Human Embryonic Kidney 293 cells (HEK293) mammalian cell line [25]. Cell lines were cultured in DMEM. Human BBS5 (EST clone reference 5272889) and mutant BBS5 (c.966dupT) and WT plasmids were subcloned into pcDNA3.1-NT-GFP vector (Invitrogen Life Technologies Ltd, UK). Following subcloning into pcDNA3.1-NT-GFP, clones were fully sequenced to confirm sequence fidelity, reading frame and orientation (data not shown). Following successful cloning, large scale preparations of plasmid cDNA were obtained using overnight culture in Luria Broth and isolation and isolation of DNA using a MaxiPrep kit (Qiagen, Manchester, UK). For transfection, Lipofectamine 2000 reagent (Life Technologies, UK) was used empirically as per the manufacturer's protocol. Cells were fixed 24 to 48 hours post transfection in $4 \%$ paraformaldehyde (PFA) and permeabilised using 0.5\% Triton-X100 (Sigma, UK) in PBS solution.

\section{Cell immunofluorescence staining}

Following blocking with 5\% BSA, cells were labelled with mouse acetylated tubulin (1:1,000; Sigma, UK) and detected using Alexa Fluor 594 donkey anti-mouse (1:200; Invitrogen Life Technologies Ltd, UK). Labelling with pericentrin antibody (1:200; Abcam, Cambridge, UK) was secondarily detected using an anti-rabbit Cy3 antibody (1:200, Invitrogen Life Technologies Ltd, UK). Cells were imaged using confocal laser scanning microscopy, (Nikon U.K. Ltd). 


\section{Statistics}

Zebrafish phenotype data was analysed using chi-squared test. Eye size and cardiac fluorescence intensity were compared using an unpaired two-sample $t$-test (MiniTab 16 software, Minitab Ltd., Coventry, UK).

\section{Results}

Molecular genetic diagnosis

We performed homozygosity mapping using SNP markers on all three affected patients and both parents of a Saudi
Arabian family (Figure 1A) where a clinical diagnosis of BBS was suspected in three of their children (Table 1). All three affected children met the current diagnostic criteria for BBS, each having 4/6 primary and 2/11 secondary BBS features.

A region of homozygosity on chromosome 2 (chr2:170, $310,006-170,383,165)$ shared by all three affected children was identified (data not shown) which included two genes: a known BBS gene, BBS5 and KBTBD10. The BBS5 gene contains 12 exons, all of which are coding and its full-
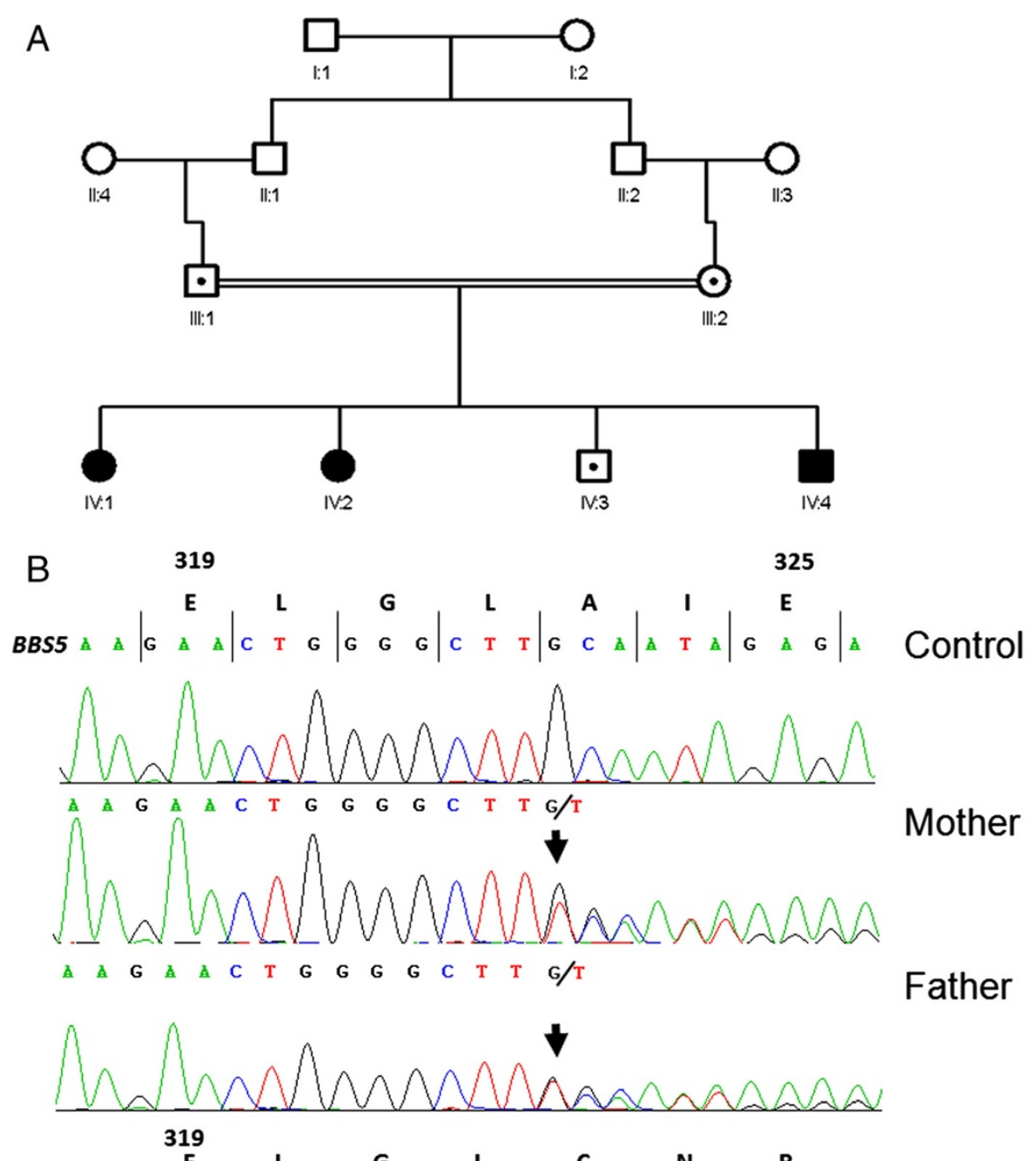

Father

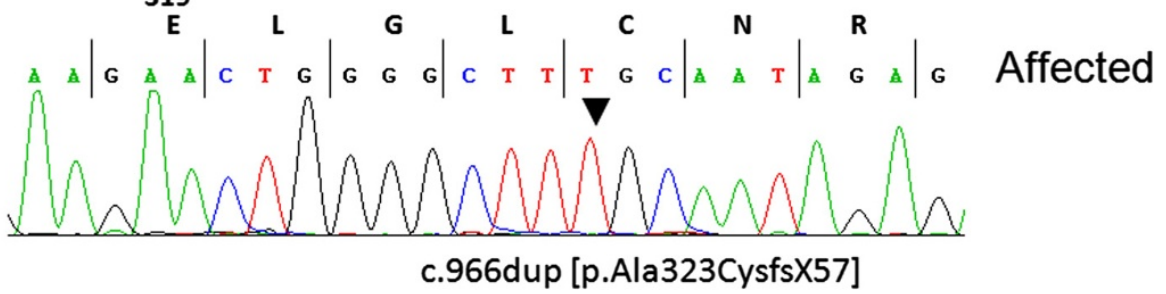

Figure 1 Family structure and molecular genetic diagnosis of a novel BBS5 mutation. (A) Pedigree diagram showing three affected siblings (shaded figures) from a consanguineous family with BBS. Circles represent females, squares represent males. Carrier (heterozygous) status is shown by a dotted symbol. (B) Sequencing chromatogram s from exon 12 of BBS5 gene showing a homozygous duplication of T nucleotide in affected son (IV:4) and segregation of the mutation from each parent. 
Table 1 Clinical features of three affected siblings

\begin{tabular}{|c|c|c|c|c|c|c|c|c|c|c|}
\hline & \multirow[b]{2}{*}{$\begin{array}{l}\text { Age at presentation } \\
\text { (years) }\end{array}$} & \multicolumn{4}{|c|}{ Primary BBS features } & \multirow[b]{2}{*}{ Hypogonadism } & \multirow[b]{2}{*}{ Obesity } & \multicolumn{3}{|c|}{ Secondary BBS features } \\
\hline & & $\begin{array}{l}\text { Post axial } \\
\text { polydactyly }\end{array}$ & $\begin{array}{l}\text { Retinal } \\
\text { dystrophy }\end{array}$ & $\begin{array}{l}\text { Renal } \\
\text { anomalies }\end{array}$ & $\begin{array}{l}\text { Learning } \\
\text { difficulties }\end{array}$ & & & $\begin{array}{l}\text { Developmental } \\
\text { delay }\end{array}$ & $\begin{array}{l}\text { Congenital } \\
\text { heart disease }\end{array}$ & Astigmatism \\
\hline Affected female & 9 & $\mathrm{Y}$ & $Y^{a}$ & $Y^{b}$ & Y & $\mathrm{n} / \mathrm{a}$ & Y & Y & $\mathrm{N}$ & Y \\
\hline Affected female & 7 & Y & N & $Y^{c}$ & Y & $\mathrm{n} / \mathrm{a}$ & Y & Y & VSD & $\mathrm{N}$ \\
\hline Affected male & 3 & Y & $\mathrm{N}$ & $\mathrm{N}$ & Y & Y & Y & Y & VSD & $\mathrm{N}$ \\
\hline
\end{tabular}

anight blindness and retinal dystrophy developed at aged 12 .

bdilatation of left renal pelvis.

cbilateral small kidneys on USS. VSD, ventricular septal defect. 
length transcript is 3,475 bp and 341 amino acid residues. Direct sequencing of all 12 coding exons of BBS5 was performed and a novel homozygous frameshift mutation c.966dupT (p.Ala323CysfsX57) in exon 12 of BBS5 was identified in all three affected individuals, with the mutation segregating from both parents (Figure 1B). The unaffected son was heterozygous for the mutation. The mutation affects a highly conserved region of the BBS5 protein and results in a predicted elongated peptide that has 379 amino acids instead of 341 in the WT. The mutation was not found in 100 DNA normal controls from a Saudi Arabian population.

\section{In vivo modelling of novel BBS5 mutation in zebrafish}

Since our main goal was to demonstrate that the c.966dupT BBS5 mutation is pathogenic, we wanted to assess whether the mutated BBS5 retains full function. One way of testing this is to perform in vivo rescue experiments and the zebrafish is a good model to use for this for a number of reasons. The zebrafish can be used to assess the pleiotropic phenotype typical of BBS, and has been used successfully to characterise phenotypes of $b b s 1, b b s 2$, bbs4, bbs5, bbs6, bbs7 and bbs8 [26,27]. The zebrafish model has also been successfully utilised to examine the effect of pair-wise BBS gene knockdown in order to study genetic interactions [27]. In addition, morphant zebrafish can be used in co-injection experiments to determine the degree of rescue of WT and mutated mRNAs.

Using zebrafish embryos, MOs were designed and injected to modify gene expression of BBS5. Delivered doses of $4 \mathrm{ng}, 6 \mathrm{ng}, 8 \mathrm{ng}$ and $12 \mathrm{ng}$ of $b b s 5$ ATG MO each produced a range of phenotypes at $72 \mathrm{hpf}$ including normal, mild, moderate and severe (Figure 2). Mild phenotypes included pericardial oedema and mild eye and tail defects. Moderate and severe phenotypes included curly tails, small eyes and prominent cardiac and pericardial oedema. There was a dose-response progression in phenotype from mild to more severe as doses increased, consistent with specificity of the bbs5 ATG MO (Figure 2E). Using a 4 ng dose, $22 \%$ of embryos displayed any phenotype, whilst a 12 ng dose produced a mild phenotype in $25 \%$, a moderate phenotype in $25 \%$ and a severe phenotype in $36 \%$ of embryos. A dose of 6 ng bbs5 ATG MO was used for subsequent phenotyping experiments. To exclude offtarget effects of bbs5 MO injection, embryos were coinjected with $6 \mathrm{ng}$ of both $p 53$ and bbs5 ATG MOs ( $\mathrm{n}=$ $144)$ or 6 ng bbs5 ATG MO alone ( $\mathrm{n}=143)$. There was no detected difference in phenotype between the two groups and they both had similar distributions of phenotypic severity (data not shown).

\section{Retinal phenotype}

Given that the 72 hpf phenotype of morphants under light microscopy included microphthalmia (Figure 3B), we attempted to quantify this further. The mean eye diameter of bbs5 ATG morphant fish with a mild to moderate phenotype was significantly smaller $(243$ pixels $(n=30))$ compared to control fish (328 pixels $(\mathrm{n}=28), P<0.001)$. Histological examination of WT embryo retina at $72 \mathrm{hpf}$ displayed normal retinal layering, with each layer appearing intact and distinct (Figure 3C). In bbs5 morphants, retinal sections demonstrated a microphthalmia with partial loss of the retinal layering. The photoreceptor layer was disrupted when compared to WT, and the lens and retina seemed to have separated from each other in the morphant embryos (Figure 3D).

\section{Cardiac phenotype}

At $48 \mathrm{hpf}$ bbs5 ATG MO injected morphant embryos displayed abnormal hearts (Figure 4B-D). In 98\% of WT embryos $(n=173)$, the hearts had a single atrium and ventricle that had undergone D-looping, resulting in the atrium being on the left side of the embryo and the ventricle on the right (Figure 4A). Morphant embryos ( $\mathrm{n}=$ 218) demonstrated L-looping in $12 \%$, resulting in the atrium being on the right side of the embryo and the ventricle on the left. A larger proportion of morphant hearts failed to loop (27\%), resulting in both the atrium and the ventricle remaining in the medial position (Figure 4E).

\section{Renal phenotype}

Pronephric duct morphology was analysed in cldnb: lynGFP embryos, which have a fluorescent pronephric duct (Figure 5A-D and Additional file 1: Figure S1). Examination of pronephric ducts under light microscopy is very subjective but examining embryos with fluorescent pronephric ducts allowed accurate phenotyping to be performed in living fish (Additional file 1: Figure S1). Dilated pronephric ducts were observed in $2 \%$ of WT embryos $(\mathrm{n}=84)$, compared to $29 \%$ of morphant embryos $(\mathrm{n}=79)$. In addition, $23 \%$ of morphant embryos displayed pronephric or cloacal cysts. No cysts were observed in WT embryos (Figure 5E). Using WT mRNA we were able to rescue the cystic phenotype. In addition, we utilised zebrafish embryos to determine evidence of kidney dysfunction, using methodology initially developed by Hentschel et al. [28]. Embryonic renal clearance in morphant zebrafish may be assessed by microinjection then subsequent tracking the elimination of a fluorescently-tagged dextran through serial image capture [29]. To estimate renal function bbs5 morphants $(\mathrm{n}=16)$ and WT $(\mathrm{n}=17)$ embryos were followed over a 48-hour period after cardiac venous sinus fluorescent dextran injection. Two morphant embryos and one WT embryo died before the end of the observation period and were excluded from the analysis. At 24 hours post dextran injection, morphant embryos retained significantly more fluorescence than WT embryos. 

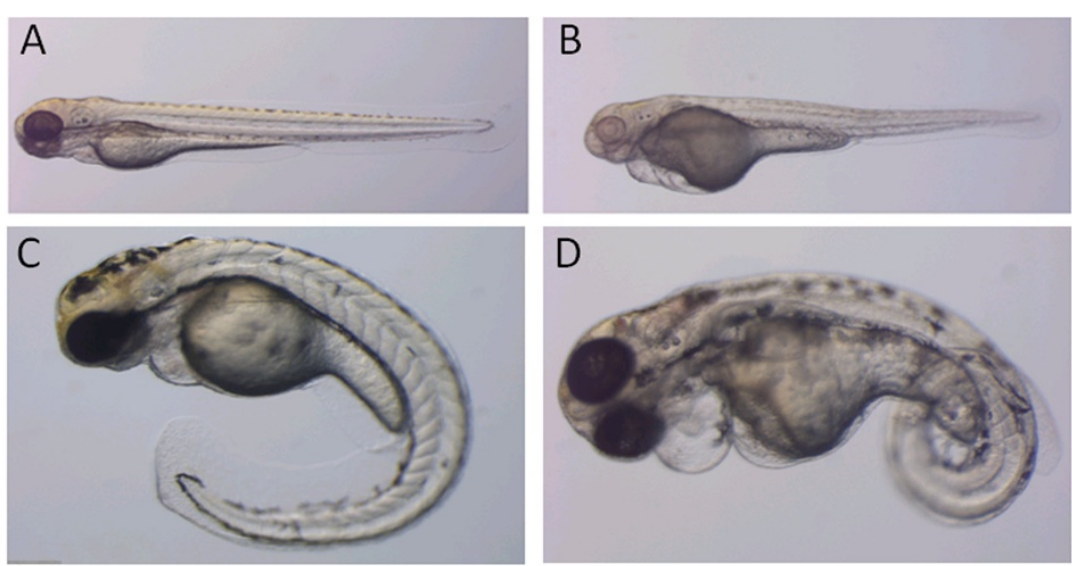

\section{E}

$$
\mathrm{n}=105
$$

$n=264$

$\mathrm{n}=109$
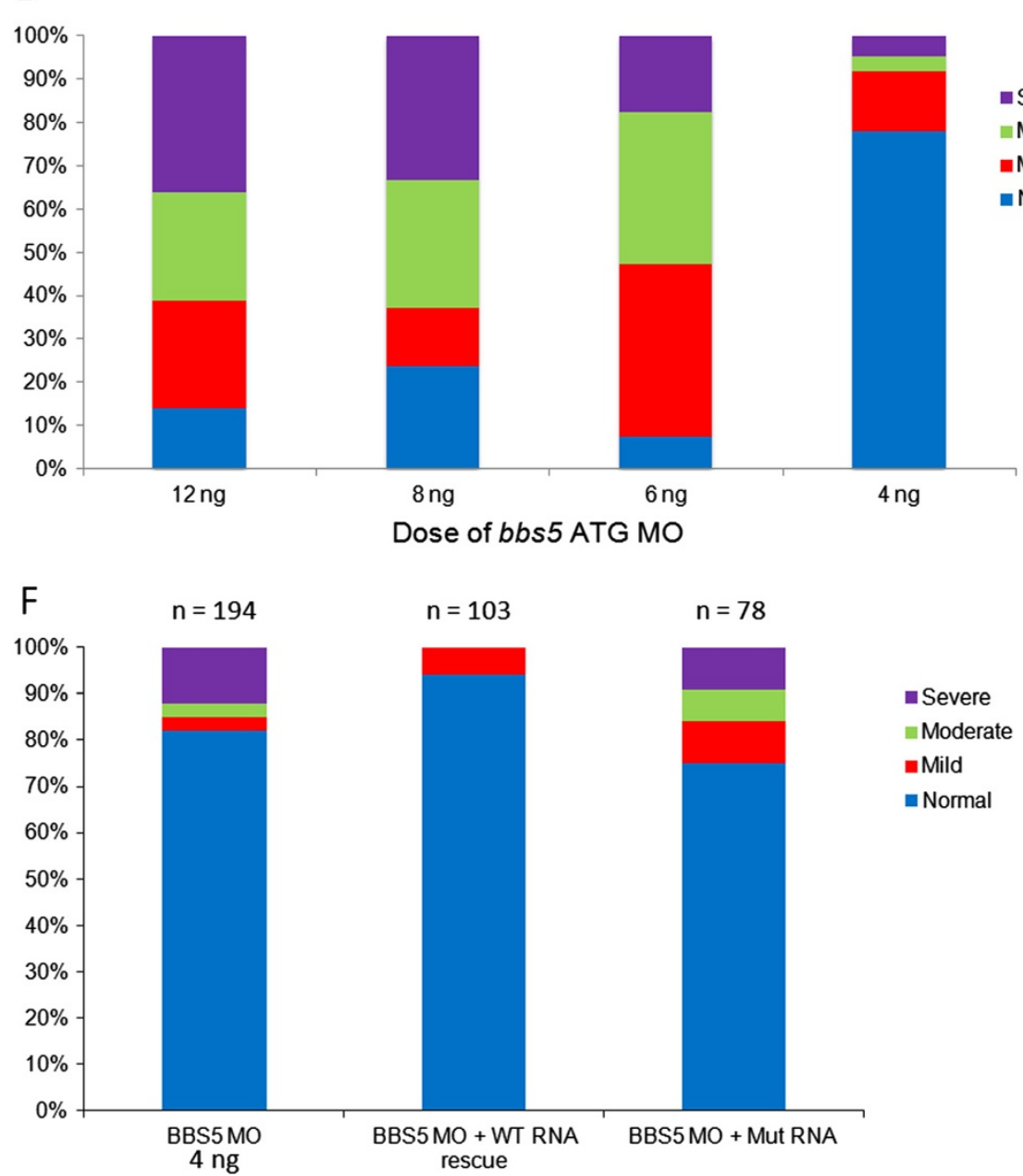

॥ Severe

$\llbracket$ Moderate

aild

- Normal

aild

normal

Figure 2 (See legend on next page.) 
(See figure on previous page.)

Figure 2 Phenotypic spectrum following bbs5 ATG MO injection and mRNA rescue. At 72 hpf following bbs5 MO injected (+/- mRNA rescue) zebrafish were phenotyped under light microscopy. Representative images are shown: (A) wildtype (WT) phenotype; (B) mildly affected morphant, showing a pericardial effusion and small eyes; (C) moderately affected morphant with a pericardial effusion, small eyes and a curly tail and (D) a severely affected morphant with a large pericardial effusion, small eyes and severe tail curvature. (E) Dose-response analysis of phenotypes following bbs5 ATG MO injection. Fish were classed phenotypically as normal if they were indistinguishable from uninjected fish; mildly affected if they had small eyes, mild pericardial effusion and mild/no tail defects; moderately affected if they had a large pericardial effusion and moderate tail defects, and severe if there was absent or very short malformed tail, widespread oedema, malformed eyes and minimal cardiac muscle contraction). Note a trend of increasing severity of phenotypes from $4 \mathrm{ng}$ to $12 \mathrm{ng} \mathrm{MO}$ dose. The number of embryos ( $\mathrm{n}$ ) injected for each dose are shown. (F) Phenotypes of bbs5 ATG MO injected fish compared to co-injected WT BBS5 mRNA and mutant (Mut) BBS5 mRNA.

The mean 24-hour post injection to 3 hours post injection fluorescence ratio was 0.630 for morphants, compared to 0.417 for WT embryos $(P=0.005)$. At 48 hours post dextran injection the 48-hour to 3-hour fluorescence ratio was 0.278 for morphants and 0.112 for WT $(P=0.002)$ (Figure 5F). This data is consistent with a reduction in renal excretory function in bbs5 morphants. Fluorescent confocal microscopy confirmed pronephric duct dilatation in bbs5 morphant embryos at $72 \mathrm{hpf}$. Interestingly, the pronephric cilia of $b b s 5$ morphants were less dense and had an irregular pattern in appearance (Figure 5G).

In order to study the pathogenic effects of novel human BBS5 mutation identified in our Saudi Arabian family, we used mutant mRNA for co-injection studies to determine its ability to rescue the morphant phenotype (Figure 2F). Injection of $4 \mathrm{ng} b b s 5 \mathrm{ATG}$ MO alone showed phenotypes in $18 \%$ of fish $(\mathrm{n}=194)$ whilst co-injection of $b b s 5$ ATG MO with WT BBS5 mRNA in an attempt to rescue the phenotype, showed only a mild (cardiac/renal/tail) phenotype in approximately $6 \%$ of fish $(n=103)$. Zebrafish demonstrating complete rescue and partial rescue of the dilated pronephros, cystic pronephros and tail phenotypes using WT BBS5 mRNA are shown in Additional file 1: Figure S1. Just 3\% of zebrafish co-injected with bbs5 ATG $\mathrm{MO}$ and WT BBS5 demonstrated a dilated pronephros. In these rescue experiments, there was an absence of moderate and severe phenotypes including situs inversus and severe tail curvature. Co-injection of bbs5 ATG

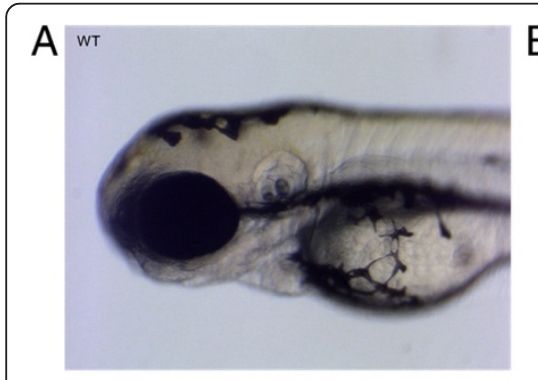

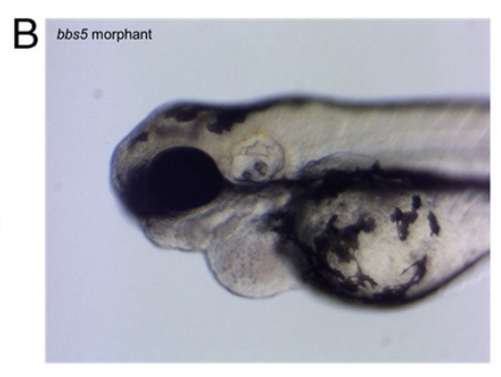

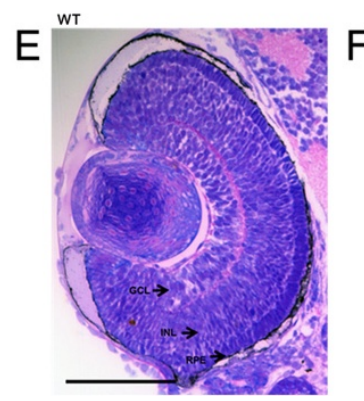

F

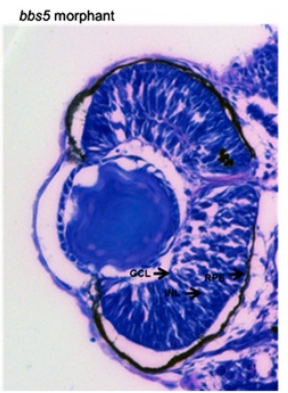

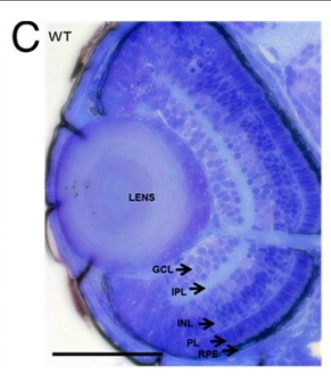
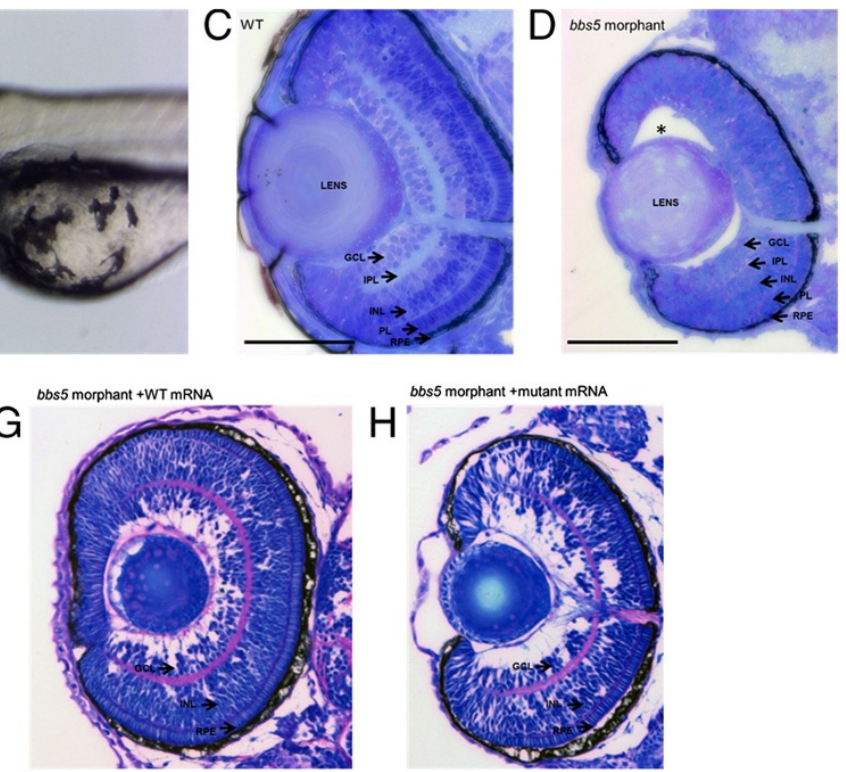

Figure 3 Microphthalmia and retinal layering defect in bbs5 morphants and phenotypic rescue with mRNA co-injection. Light microscopy of $72 \mathrm{hpf}$ embryos show a reduction in eye size in between (A) wildtype (WT) and (B) bbs5 morphants. Retinal sections demonstrating (C) WT retina with normal, well demarcated retinal layering compared to (D) morphant retina displaying partial loss of retinal layering, loss of photoreceptor layer and separation of lens from retina (*). In mRNA rescue experiments, WT mRNA or mutant mRNA was co-injected with bbs5 MO. (E) Retinal layers are preserved in WT and (F) disrupted in bbs5 morphants. (G) WT mRNA is able to rescue the retinal phenotype and eye size whilst in the (H) mutant mRNA phenotype retinal layers remain disrupted and the eye size small. Scale bar 100 um. GCL, ganglion cell layer; INL, inner nuclear layer; IPL, inner plexiform layer; PL, photoreceptor layer, RPE, retinal pigment epithelia. 

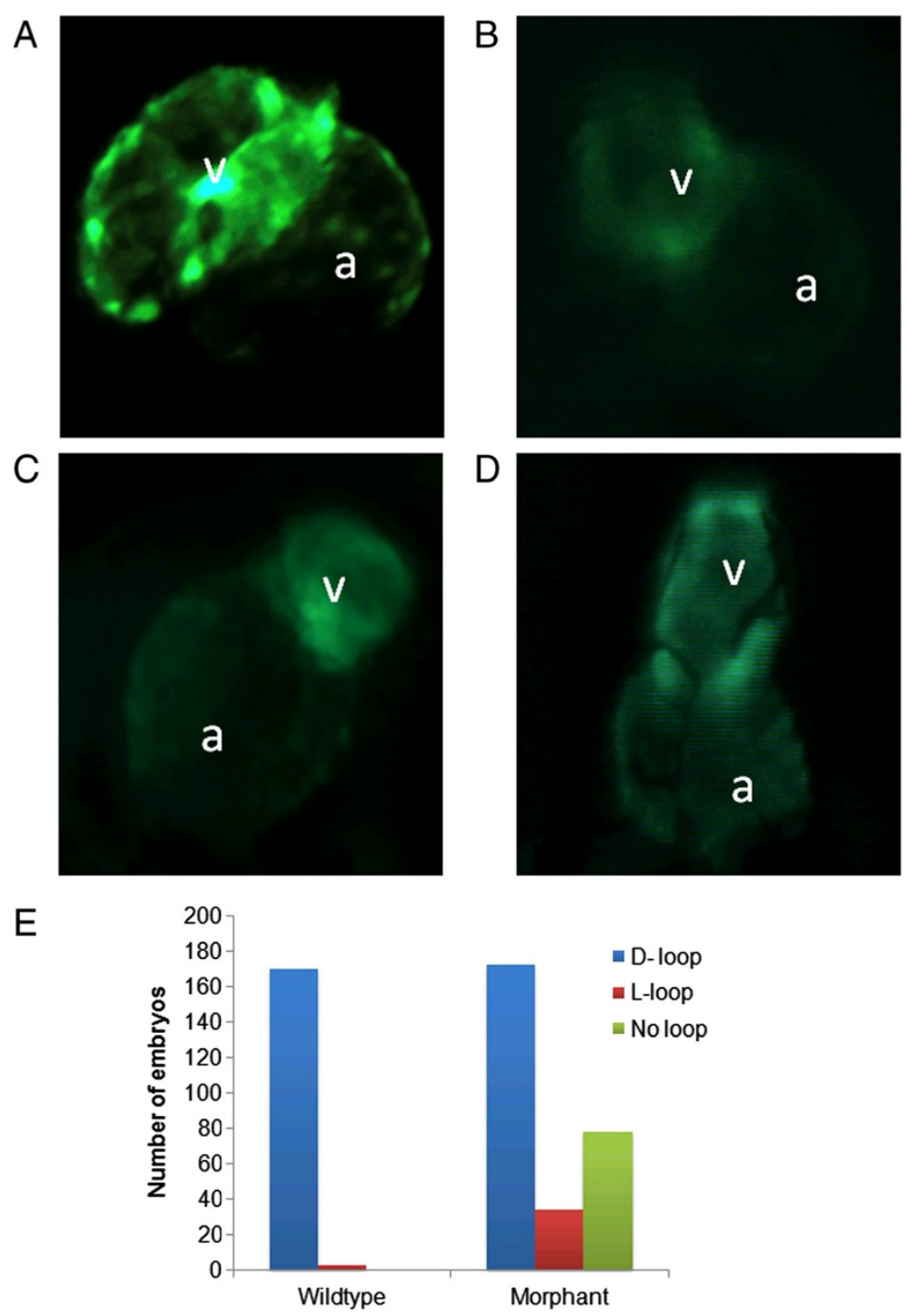

Figure 4 bbs5 morphants display cardiac anomalies including situs inversus. Wildtype (WT) and morphant cmlc2:GFP embryos were imaged at $48 \mathrm{hpf}$. (A) WT heart showing normal looping (D-looping) with the atrium (a) on the left hand side of the embryo and the ventricle (v) on the right. (B) Morphant heart with preserved D-looping. (C) Morphant heart with looping in the opposite direction (L-looping) resulting in the atrium on the right of the embryo and the ventricle on the left. (D) Morphant heart, which shows a failure of looping, resulting in a heart with neither the atrium nor ventricle leaving the midline. (E) $98 \%$ of WT embryos displayed D-looping whilst just $61 \%$ of morphant embryos exhibited D-looping, 12\% exhibited L-looping, and 27\% of morphant hearts were unlooped $(P<0.001)$.

MO with mutated BBS5 mRNA (c.966dupT) showed a (cardiac/renal/tail) phenotype in $25 \%$ of fish embryos $(\mathrm{n}=78)$, including $9 \%$ severe and $7 \%$ with moderate phenotypes (Figure 2F). These experiments point to the direct pathogenicity of the c.966dupT mutation. Furthermore, histological examination of retina from morphant embryos co-injected with WT mRNA showed a recovery of the retinal layering phenotype (Figure 3G) and correction of eye size (Figure 3G). In contrast, co-injection with mutant mRNA failed to rescue the phenotype with disruption of retinal layering remaining (Figure $3 \mathrm{H}$ ). Western blotting at 48 hours was used to confirm expression of the
WT and c.966dupT mutated BBS5-NT-GFP proteins (Additional file 2: Figure S2).

\section{Localisation of wildtype and mutant BBS5-NT-GFP in HEK293 cells}

WT and mutant BBS5-NT-GFP were transfected into HEK293 cells to assess the pathogenicity of the mutation detected (c.966dupT) at the cellular level. BBS proteins typically localize to the basal body of ciliated cells [30]. A basal body localization of WT BBS5-NT-GFP protein in HEK293 was demonstrated with colocalisation of BBS5NT-GFP and pericentrin (Figure 6A,B). Transfection of the 


\section{A}

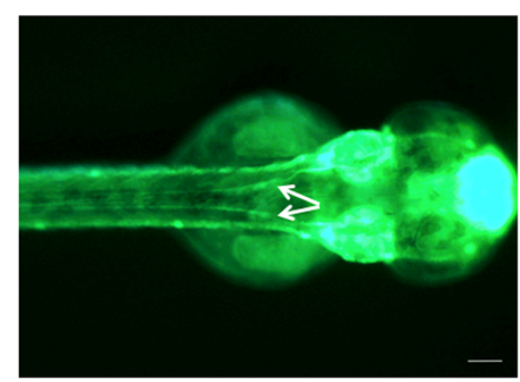

C

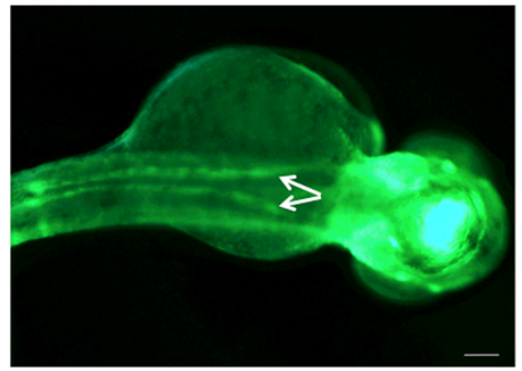

E

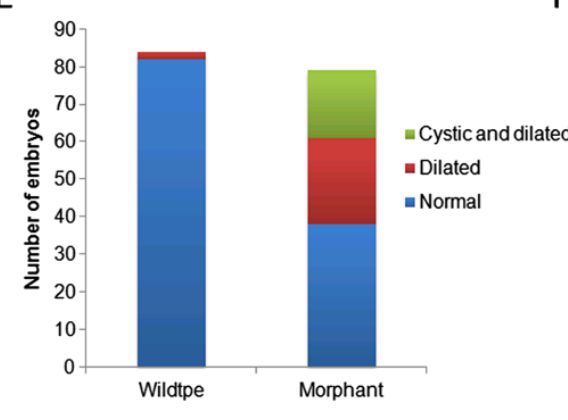

G
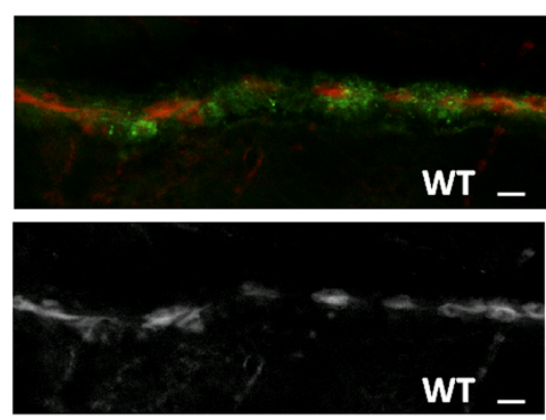

$\mathrm{F}$

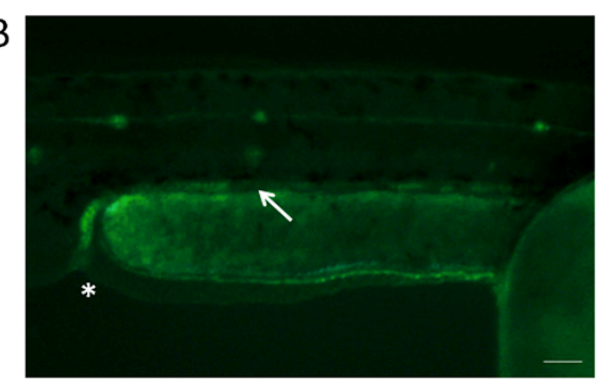

D
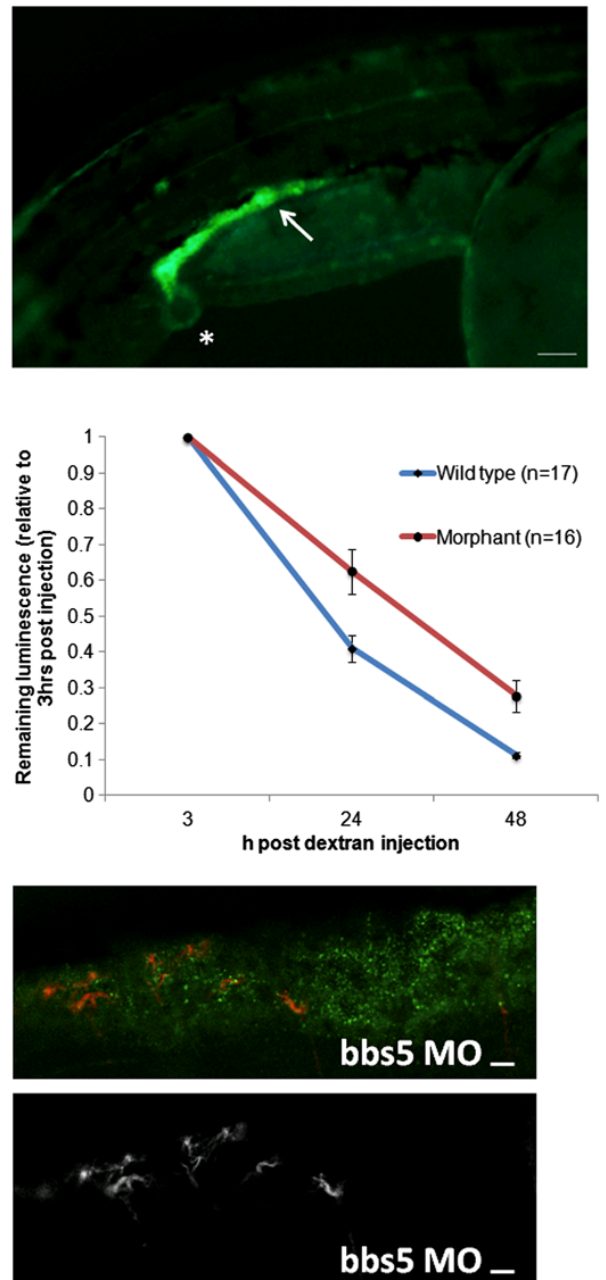

Figure 5 Characterisation of pronephros structure and function in bbs 5 morphants. (A-D) Superior and lateral views of a cldnb:lynGFP embryo displaying $(\mathbf{A}, \mathbf{B})$ normal pronephric ducts (arrowed) and cloaca $\left(^{*}\right)$ in wildtype (WT) zebrafish. (C,D) bbs5 morphant embryos displayed dilated and tortuous pronephric ducts (identified by GFP fluorescence) and a (D) cloacal cystic dilatation. Scale bars are 100 um. (E) Quantification of pronephros abnormalities in WT and bbs5 morphant embryos. (F) Estimation of GFR in zebrafish embryos was performed by measuring change in cardiac luminosity of both WT and morphant embryos after cardiac sinus fluorescent dextran injection. Mean luminescence $+/$ - SEM (arbitrary units) is plotted versus time, up to 48 hours post injection. Morphant embryos retained significantly more fluorescent dextran at 24 hours $(P=0.005)$ and at 48 hours $(P=0.002)$. (G) At 72 hpf, compared to WT control, bbs5 morphant embryos revealed disrupted and fewer numbers of cilia in the dilated pronephros. Scale bar $10 \mu \mathrm{m})$.

c.966dupT mutant BBS5-NT-GFP mRNA led to a loss of discrete basal body localisation (with loss of colocalisation with pericentrin) and an intracellular diffuse localisation (Figure 6C,D).

\section{Discussion}

$\mathrm{BBS}$ is a genetically heterogeneous disorder. To date, mutations in 18 genes (BBS1-18) are known to cause the phenotype $[14,16]$. Bioinformatics analysis of these genes 

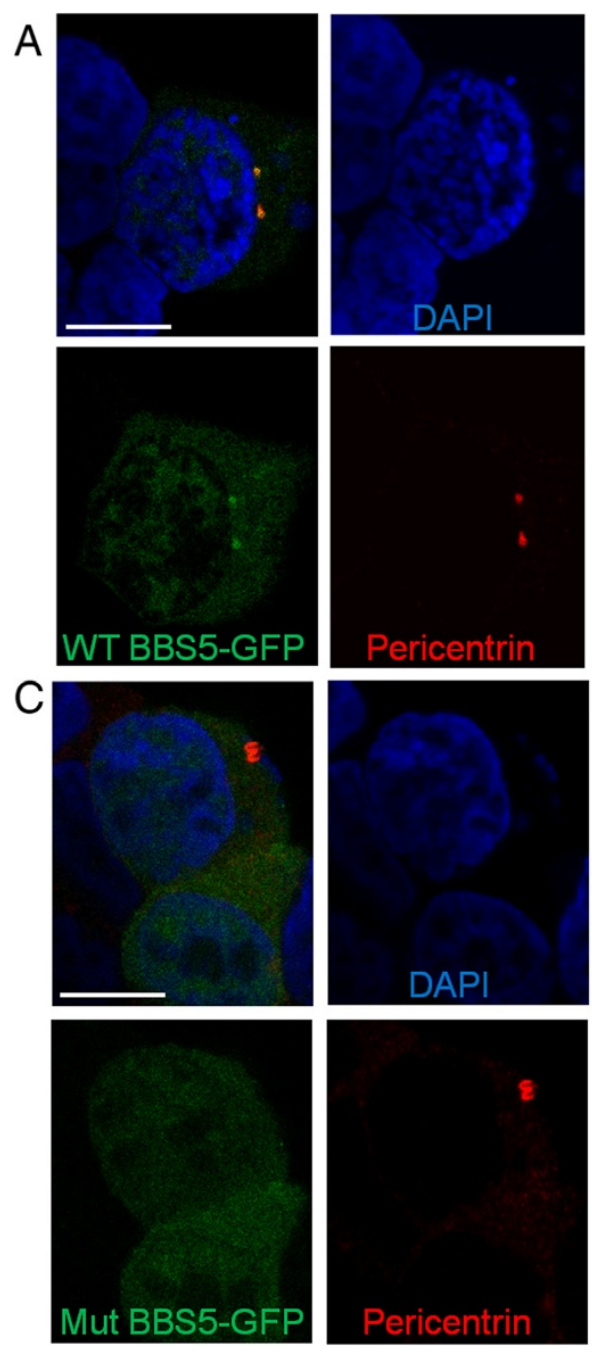

Figure 6 Comparison of wildtype (WT) and mutant BBS5-NT-GFP expression and localisation in HEK293 cells. Confocal fluorescent images (overlay, plus individual fluorescent channels respectively) from WT BBS5-NT-GFP (A,B) and mutant (Mut) BBS5-NT-GFP (C,D) are shown, together with pericentrin antibody (red) to localise centrosomes. The stain 4'-6-diamidino-2-phenylindole (DAPI) (blue) is used to stain nuclei.

(A) WT BBS5-NT-GFP colocalises with pericentrin at centrosomes. There is some diffuse cytoplasmic and intranuclear localisation of WT BBS5-NT-GFP. (B) WT BBS5-NT-GFP colocalises with pericentrin at the centrosomes in a cell undergoing mitosis. (C,D) Mut BBS5-NT-GFP is distributed diffusely throughout the cell and fails to colocalise with the centrosomal marker pericentrin. Scale bar $10 \mu \mathrm{m}$.

demonstrates that the majority of BBS genes are not genetic duplications, but are distinct genes encoding for proteins in a linked pathway [18]. In BBS, the most commonly mutated genes are BBS1 and BBS10, accounting for $23 \%$ and $21 \%$ of cases respectively [31]. BBS5 mutations are rare, with only 0.4 to $2 \%$ of cases linked to a mutation in this gene [17,31].

The intracellular role of BBS proteins has only recently begun to be understood. A breakthrough in understanding the function of BBS proteins came with the proposal by Nachury et al. which detailed that BBS1,2,4,5,7-9 form a functional complex named the BBSome [18]. They observed that these proteins were found in stoichiometric amounts after purification and identification
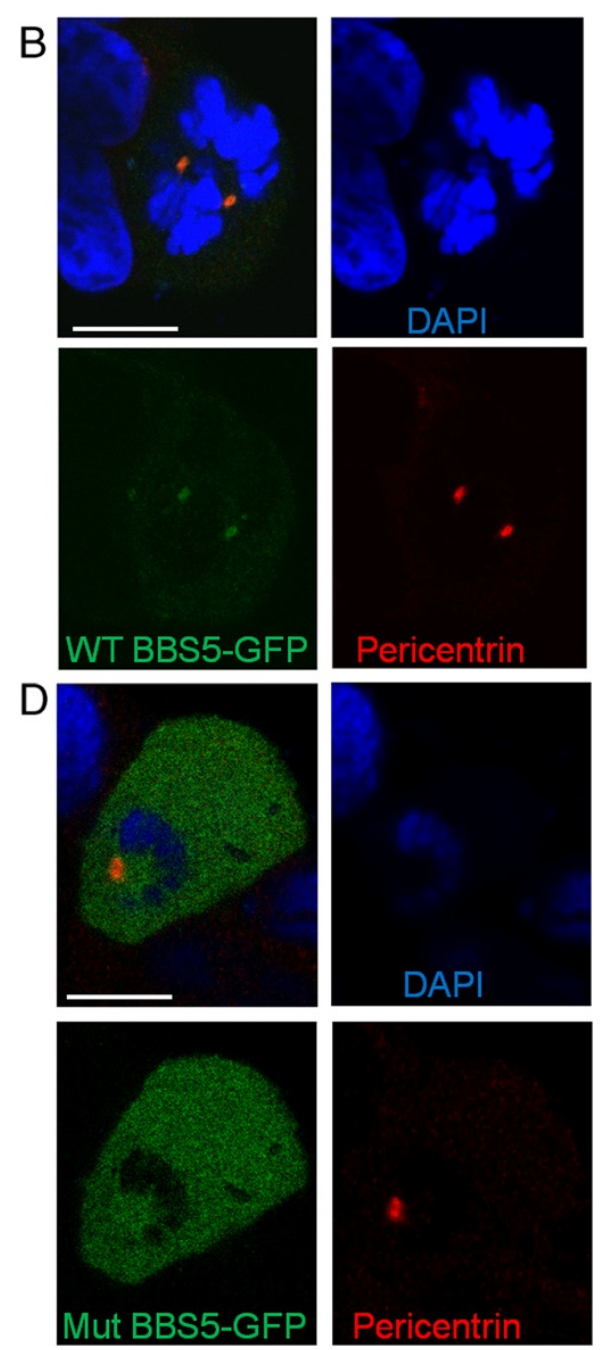

with mass spectrometry, and that these proteins cofractionate together [18]. Interestingly, the BBSome proteins are highly conserved across ciliated organisms [18]. The BBSome associates with both the ciliary membrane and with Rab8, a GTPase which is known to promote vesicular transport to the cell membrane [32]. BBS3 (or ARL6), while not a BBSome protein, is also a GTPase and thought to localise to the ciliary membrane assembly point at the base of the cilium [33], and has been shown to associate with the BBSome [34]. The BBSome localises with intraflagellar transport (IFT) particles as it travels the length of C. reinhardtii flagella [35] but does not seem to be a core component of the IFT complex [35]. Instead, it is proposed that the BBSome acts as an 
adaptor for protein cargo that is transported up the cilia by IFT [35]. These studies come together to present the current hypothesis that the BBSome, together with Rab8 and BBS3, function as adapters between vesicular bound proteins and IFT proteins to promote ciliary membrane biogenesis.

For many years, analysis of families with BBS showed evidence of a fifth locus for the disorder at position 2q31 $[1,36]$ but it was not until a study by Li et al. in 2004 that the BBS5 gene was discovered using an elegant comparative genomics method [17]. They hypothesised that unknown genes related to ciliary function will not be present in an organism without cilia, Arabidopsis, but present in organisms with cilia, humans and Chlamydomonas [17]. BBS5 is conserved and present in at least 23 orthologues including Toxoplasma gondii [18]. The molecular genetic diagnosis of patients with BBS is challenging because of genetic heterogeneity of BBS. We and others have shown that homozygosity mapping is a robust approach that is highly suited for genetically heterogeneous autosomal recessive disorders in populations in which consanguinity is highly prevalent. This approach of using genechip platforms of genome wide SNPs helped identify a disease locus. In the family we report, homozygosity mapping directly targeted $B B S 5$ as the likely cause. Phenotype-genotype correlation is typically very poor in BBS. Although we detected a mutation in $B B S 5$, the phenotype we report resembles reported phenotypes from same population who had mutations in $B B S 1, B B S 3$, and BBS4 [37].

In our family, the BBS5 c.966dupT (p.Ala323CysfsX57) novel mutation led to a predicted elongation of the BBS protein following a change in the reading frame. To date, there are 17 previously reported mutations in $B B S 5$, which include missense [17,38-43], splice site mutations $[17,43]$ and small deletions/insertions $[17,43,44]$. However, to our knowledge a mutation that leads to a predicted elongation of the BBS5 protein has not previously been reported. Additional studies including RTPCR studies and Western blotting of BBS5 protein from affected patients would be required to confirm the predicted effect of the mutation on mRNA and protein, respectively. Unfortunately this was not feasible.

In order to determine the pathogenicity of the $B B S 5$ mutation, we used MO injection of zebrafish embryos. The zebrafish $b b s 5$ shares $90.9 \%$ protein identity with human BBS5 which allows specific modelling of human mutations. Data on a limited number (40 to 50) of bbs5 knockout zebrafish embryos have been previously reported [26]. These embryos demonstrated abnormal Kupffer's vesicles (KV), altered heart looping and abnormal melanosome transport. These findings show convincing evidence that $B B S 5$ is a ciliopathy gene with roles in multiple developmental processes.
Using mutant BBS5 mRNA to 'rescue' the phenotype of bbs5 ATG MO, we saw an enhanced number of embryos with a disease phenotype. In addition, the eye and retinal phenotype remained severe. These data suggest that the c.966dupT mutation is indeed pathogenic, although the exact mechanism is not clear. A number of possible mechanisms can be speculated. As BBS5 is part of the BBSome, the mutation may affect other BBSome proteins and the localisation and function of the BBSome. The loss of the WT C-terminal amino acids may lead to the mislocalisation of BBS5 protein and a series of Cterminal-truncating mutations could be used to identify such a centrosomal localisation motif.

A systematic approach to using zebrafish to evaluate human mutations in BBS genes has previously been reported [45] where a significant number of BBS-associated mutations were suggested to have a dominant-negative mode of action. Evidence was provided in zebrafish embryos that certain mutant mRNAs produced phenotypes significantly worse than $\mathrm{MO}$ alone [45]. However, it must be remembered that when using over-expression systems, there is the possibility of inducing an over-expression defect that is not relevant to the human condition.

Using zebrafish as a model for ciliopathies is well established, with reported models of Joubert syndrome $[21,46,47]$, Meckel-Gruber syndrome, [48,49] Jeune syndrome [50] and nephronophthisis [51-53]. There have also been several other reported zebrafish models of BBS $[26,29,54,55]$ again demonstrating retinal defects, defective melanosome transport, abnormal left-right determination with defective heart looping, abnormal KVs with defective cilia and kidney anomalies [26,29,54,55]. The establishment of left-right asymmetry in the zebrafish is secondary to an asymmetric fluid flow in $\mathrm{KV}$, resulting in asymmetric gene expression across the whole of the developing embryo [56]. The abnormal cardiac looping secondary to $b b s$ gene knockdown shown here and by others [26] is likely to be secondary to a cilial defect within KV and part of a generalised laterality defect.

In bbs5 morphant zebrafish, we have demonstrated dilatation as well as pronephric and cloacal cysts. Furthermore, in the $b b s 5$ morphants we were able to demonstrate a reduction in renal excretory function. In zebrafish, cilia in the pronephros are motile and are important for driving fluid flow within these organs. Disruption of cilia structure or motility in the pronephros leads to fluid accumulation and cystic dilatation [57]. In bbs5 morphants, the pronephic ducts, as well being dilated, had a reduced and irregular pattern of cilia.

Within the family we describe there were renal anomalies in two out of the three affected siblings. Renal anomalies have a reported prevalence in BBS patients of $24 \%$, although only $52 \%$ of patients had undergone an investigative renal examination [58]. Renal anomalies may be 
structural changes such as renal parenchymal cysts, calyceal clubbing, foetal lobulation, dysplastic kidneys, unilateral agenesis, hydronephrosis and horseshoe kidney implicating BBS5 in normal renal development [58]. A progressive decline in renal function in BBS patients may also be seen and may be secondary to vesicouretic reflux and obstruction leading to scarring. Renal disease is a major cause of mortality in BBS patients. Reviewing 20 BBS patients, it was revealed that all patients had either structural or functional renal abnormalities and three had established renal failure [59]. The functional defects included inability to concentrate urine and renal tubular acidification defects, implicating a dysfunctional renal collecting duct in a similar manner to nephronophthisis [60]. Chronic kidney disease progressing to established renal failure is a significant cause of morbidity and mortality in patients with BBS [8]. The findings of pronephric dilatation, together with reduced excretory function in bbs 5 morphants, implicate bbs 5 in both renal development and functional maintenance of the pronephros. We speculate that these defects may be secondary to renal ciliary dysfunction where bbs proteins coordinate ciliary proteins and ciliary signalling. Remarkably, these zebrafish morphant studies of $b b s$ genes demonstrate a high degree of concordance and fit well with phenotypes reported in humans. Taken together with our data, we confirm that zebrafish are a valid model for the study of BBS genes.

At a cellular level, genes that are mutated in ciliopathies can affect ciliary signalling in different ways. This may be through changes in cilia structure, in mistargeting of signalling molecules or effecting the sensory role of primary cilia [61]. It is known that BBS5 protein is localized to basal bodies just beneath the cilia [17]. We confirm a basal body localisation for GFP-tagged BBS5, which became mislocalised upon introduction of the mutation. The (p.Ala323CysfsX57) mutation affects the C-terminal amino acids of the BBS5 protein and does not disrupt the PH domains of BBS5 [18]. Previously, it has been shown that following BBS5 knockdown, centrin and pericentrin were still targeted to centrosomes and centriolar satellite function remained intact, however ciliogenesis was disrupted [18]. In HEK293 cells transfected with mutant BBS5, we confirm a normal expression pattern of pericentrin with complete loss of colocalisation with BBS5. This data is comparable to the BBS4 mutant allele L327P, which failed to colocalise with $\gamma$-tubulin in post-mitotic cells [45].

\section{Conclusions}

In conclusion we describe a consanguineous Saudi Arabian family with clinical features of BBS, together with a novel mutation in BBS5. Modelling this disease in zebrafish mimics the human disease, and pathogenicity of the novel
BBS5 mutation is demonstrated by the inability of mutant mRNA to rescue morphant zebrafish phenotype as well as mislocalisation of mutant BBS5 protein in renal epithelial cells.

\section{Additional files}

Additional file 1: Figure S1. Light and fluorescence microscopy of renal cysts in bbs5 morphants and rescue with WT bbs5 mRNA. Left panels show bright-field images of $72 \mathrm{hpf}$ embryos and right panels show immunofluorescence images, using claudin-Lyn-GFP embryos which express GFP throughout the pronephros (as well as forebrain and ear). (A,B) Uninjected fish (Control). (C-H) Morphological defects are seen in b65 morphant embryos. bbs5 morphant embryos show pronephros dilatation and cyst formation which is subtle on light microscopy (black arrows) but more easily identified under fluorescence microscopy (white arrows). (I-N) Morphant phenotypes of tail abnormalities, pronephric duct dilatation /cysts are (I-L) partially and $(\mathrm{M}, \mathrm{N})$ fully rescued by co-injection with WT bbs5 mRNA

Additional file 2: Figure S2. Expression of WT and mutant BBS5-NT-GFP. Western blotting confirming protein expression of the predicted size (arrowed) for WT and mutant BBS-NT-GFP (predicted molecular weight $45 \mathrm{kDa}$ BBS5 + $27 \mathrm{kDa}$ GFP $=72 \mathrm{kDa})$.

\section{Abbreviations}

BBS: Bardet-Biedl Syndrome; HEK: Human Embryonic Kidney; hpf: hours post fertilisation; IFT: intraflagellar transport; KV: Kupffer's vesicle; MO: Morpholino Oligonucleotide; PFA: paraformaldehyde; PH: Pleckstrin Homology; WT: Wild Type.

\section{Competing interests}

The authors declare that they have no competing interests.

\section{Authors' contributions}

MHA-H carried out the molecular genetic studies, cell studies, performed zebrafish studies and drafted the manuscript. CVL, PC, RES and RJS performed zebrafish studies and drafted the manuscript. FA-F and BM helped conceive the study, recruited the patients and performed clinical studies. $\mathrm{AMH}$ and LE performed molecular and cell studies and drafted the manuscript. JAS conceived of the study, and participated in its design and coordination, performed zebrafish and cell studies and drafted the manuscript. All authors read and approved the final manuscript.

\section{Acknowledgements}

This work is supported by the Northern Counties Kidney Research Fund.

\section{Author details}

${ }^{1}$ International Centre for Life, Institute of Genetic Medicine, Newcastle University, Central Parkway, Newcastle NE1 3BZ, UK. ${ }^{2}$ Genetics Department King Faisal Specialist Hospital and Research Centre, PO Box 3354, Riyadh 11211, Saudi Arabia. ${ }^{3}$ Department of Paediatrics, Maternity \& Children's Hospital, PO Box 6205, Al Madina, Al Munawara, Saudi Arabia. ${ }^{4}$ Department of Clinical and Chemical Pathology, Kasr Al-Ainy Faculty of Medicine, Cairo University, Cairo, Egypt.

Received: 22 April 2013 Accepted: 4 February 2014 Published: 21 Feb 2014

\section{References}

1. Beales PL, Warner AM, Hitman GA, Thakker R, Flinter FA (1997) Bardet-Bied syndrome: a molecular and phenotypic study of 18 families. J Med Genet 34:92-98

2. Klein D, Ammann F (1969) The syndrome of Laurence-Moon-Bardet-Bied and allied diseases in Switzerland: clinical, genetic and epidemiological studies. J Neurol Sci 9:479-513

3. Moore SJ, Green JS, Fan Y, Bhogal AK, Dicks E, Fernandez BA, Stefanelli M, Murphy C, Cramer BC, Dean JC, et al. (2005) Clinical and genetic epidemiology of Bardet-Biedl syndrome in Newfoundland: a 22-year prospective, population-based, cohort study. Am J Med Genet A $132: 352-360$ 
4. Farag TI, Teebi AS (1989) High incidence of Bardet-Biedl syndrome among the Bedouin. Clin Genet 36:463-464

5. Rahman $\mathrm{P}$, Jones A, Curtis J, Bartlett $\mathrm{S}$, Peddle L, Fernandez BA, Freimer NB (2003) The Newfoundland population: a unique resource for genetic investigation of complex diseases. Hum Mol Genet 12 Spec Number 2:R167-R172

6. Teebi AS (2010) Genetic disorders among Arab populations, 2nd edition. Springer

7. Beales PL, Elcioglu N, Woolf AS, Parker D, Flinter FA (1999) New criteria for improved diagnosis of Bardet-Biedl syndrome: results of a population survey. J Med Genet 36:437-446

8. O'Dea D, Parfrey PS, Harnett JD, Hefferton D, Cramer BC, Green J (1996) The importance of renal impairment in the natural history of Bardet-Biedl syndrome. Am J Kidney Dis 27:776-783

9. Putoux A, Attie-Bitach T, Martinovic J, Gubler MC (2012) Phenotypic variability of Bardet-Biedl syndrome: focusing on the kidney. Pediatr Nephrol 27:7-15

10. Riise R, Andreasson S, Borgastrom MK, Wright AF, Tommerup N, Rosenberg T, Tornqvist K (1997) Intrafamilial variation of the phenotype in Bardet-Biedl syndrome. Br J Ophthalmol 81:378-385

11. Elbedour K, Zucker N, Zalzstein E, Barki Y, Carmi R (1994) Cardiac abnormalities in the Bardet-Biedl syndrome: echocardiographic studies of 22 patients. Am J Med Genet 52:164-169

12. Deffert C, Niel F, Mochel F, Barrey C, Romana C, Souied E, Stoetzel C, Goossens M, Dollfus H, Verloes A, et al. (2007) Recurrent insertional polydactyly and situs inversus in a Bardet-Biedl syndrome family. Am J Med Genet A 143:208-213

13. Kulaga HM, Leitch CC, Eichers ER, Badano JL, Lesemann A, Hoskins BE, Lupski JR, Beales PL, Reed RR, Katsanis N (2004) Loss of BBS proteins causes anosmia in humans and defects in olfactory cilia structure and function in the mouse. Nat Genet 36:994-998

14. Forsythe E, Beales PL (2013) Bardet-Biedl syndrome. Eur J Hum Genet 21:8-13

15. Marion V, Stutzmann F, Gerard M, De Melo C, Schaefer E, Claussmann A, Helle S, Delaque V, Souied E, Barrey C, et al. (2012) Exome sequencing identifies mutations in LZTFL1, a BBSome and smoothened trafficking regulator, in a family with Bardet-Biedl syndrome with situs inversus and insertional polydactyly. J Med Genet 49:317-321

16. Scheidecker S, Etard C, Pierce NW, Geoffroy V, Schaefer E, Muller J, Chennen K, Flori E, Pelletier V, Poch O, et al. (2014) Exome sequencing of Bardet-Biedl syndrome patient identifies a null mutation in the BBSome subunit BBIP1 (BBS18). J Med Genet 51:132-6.

17. Li JB, Gerdes JM, Haycraft CJ, Fan Y, Teslovich TM, May-Simera H, Li H, Blacque OE, Li L, Leitch CC, et al. (2004) Comparative genomics identifies a flagellar and basal body proteome that includes the BBS5 human disease gene. Cell 117:541-552

18. Nachury MV, Loktev AV, Zhang Q, Westlake CJ, Peranen J, Merdes A, Slusarski DC, Scheller RH, Bazan JF, Sheffield VC, Jackson PK (2007) A core complex of BBS proteins cooperates with the GTPase Rab8 to promote ciliary membrane biogenesis. Cell 129:1201-1213

19. Jean S, Kiger AA (2012) Coordination between RAB GTPase and phosphoinositide regulation and functions. Nat Rev Mol Cell Biol 13:463-470

20. Huang CJ, Tu CT, Hsiao CD, Hsieh FJ, Tsai HJ (2003) Germ-line transmission of a myocardium-specific GFP transgene reveals critical regulatory elements in the cardiac myosin light chain 2 promoter of zebrafish. Dev Dyn 228:30-40

21. Simms RJ, Hynes AM, Eley L, Inglis D, Chaudhry B, Dawe HR, Sayer JA (2011) Modelling a ciliopathy: Ahi1 knockdown in model systems reveals an essential role in brain, retinal, and renal development. Cell Mol Life Sci 69:993-1009.

22. Detrich WH, Westerfield M, Zon LI (2011) The zebrafish: genetics, genomics and informatics. In: Wilson L, Matsudaira PT (ed) Methods in Cell Biology, 104th edition. Academic Press

23. Robu ME, Larson JD, Nasevicius A, Beiraghi S, Brenner C, Farber SA, Ekker SC (2007) p53 activation by knockdown technologies. PLoS Genet 3:e78

24. Bedell VM, Westcot SE, Ekker SC (2011) Lessons from morpholino-based screening in zebrafish. Brief Funct Genomics 10:181-188

25. Graham FL, Smiley J, Russell WC, Nairn R (1977) Characteristics of a human cell line transformed by DNA from human adenovirus type 5. J Gen Virol 36:59-74

26. Yen HJ, Tayeh MK, Mullins RF, Stone EM, Sheffield VC, Slusarski DC (2006) Bardet-Biedl syndrome genes are important in retrograde intracellular trafficking and Kupffer's vesicle cilia function. Hum Mol Genet 15:667-677

27. Tayeh MK, Yen HJ, Beck JS, Searby CC, Westfall TA, Griesbach H, Sheffield VC, Slusarski DC (2008) Genetic interaction between Bardet-Biedl syndrome genes and implications for limb patterning. Hum Mol Genet 17:1956-1967
28. Hentschel DM, Park KM, Cilenti L, Zervos AS, Drummond I, Bonventre JV (2005) Acute renal failure in zebrafish: a novel system to study a complex disease. Am J Physiol Renal Physiol 288:F923-F929

29. Tobin $J L$, Beales PL (2008) Restoration of renal function in zebrafish models of ciliopathies. Pediatr Nephrol 23:2095-9.

30. Fan Y, Esmail MA, Ansley SJ, Blacque OE, Boroevich K, Ross AJ, Moore SJ, Badano JL, May-Simera H, Compton DS, et al. (2004) Mutations in a member of the Ras superfamily of small GTP-binding proteins causes Bardet-Biedl syndrome. Nat Genet 36:989-993

31. Katsanis N (2004) The oligogenic properties of Bardet-Biedl syndrome. Hum Mol Genet 13 Spec No 1:R65-R71

32. Knodler A, Feng S, Zhang J, Zhang X, Das A, Peranen J, Guo W (2010) Coordination of Rab8 and Rab11 in primary ciliogenesis. Proc Natl Acad Sci U S A 107:6346-6351

33. Wiens $\mathrm{CJ}$, Tong Y, Esmail MA, Oh E, Gerdes JM, Wang J, Tempel W, Rattner JB, Katsanis N, Park HW, Leroux MR (2010) Bardet-Biedl syndrome-associated small GTPase ARL6 (BBS3) functions at or near the ciliary gate and modulates Wnt signalling. J Biol Chem 285:16218-16230

34. Zhang Q, Nishimura D, Seo S, Vogel T, Morgan DA, Searby C, Bugge K, Stone EM, Rahmouni K, Sheffield VC (2011) Bardet-Biedl syndrome 3 (Bbs3) knockout mouse model reveals common BBS-associated phenotypes and Bbs3 unique phenotypes. Proc Natl Acad Sci U S A 108:20678-20683

35. Lechtreck KF, Johnson EC, Sakai T, Cochran D, Ballif BA, Rush J, Pazour GJ, Ikebe M, Witman GB (2009) The Chlamydomonas reinhardtii BBSome is an IFT cargo required for export of specific signalling proteins from flagella. J Cell Biol 187:1117-1132

36. Young TL, Penney L, Woods MO, Parfrey PS, Green JS, Hefferton D, Davidson WS (1999) A fifth locus for Bardet-Biedl syndrome maps to chromosome 2q31. Am J Hum Genet 64:900-904

37. Abu Safieh L, Aldahmesh MA, Shamseldin H, Hashem M, Shaheen R, Alkuraya H, Al Hazzaa SA, Al-Rajhi A, Alkuraya FS (2010) Clinical and molecular characterisation of Bardet-Biedl syndrome in consanguineous populations: the power of homozygosity mapping. J Med Genet 47:236-241

38. Muller J, Stoetzel C, Vincent MC, Leitch CC, Laurier V, Danse JM, Helle S, Marion V, Bennouna-Greene V, Vicaire S, et al. (2010) Identification of 28 novel mutations in the Bardet-Biedl syndrome genes: the burden of private mutations in an extensively heterogeneous disease. Hum Genet 127:583-593

39. Harville HM, Held S, Diaz-Font A, Davis EE, Diplas BH, Lewis RA, Borochowitz ZU, Zhou W, Chaki M, MacDonald J, et al. (2010) Identification of 11 novel mutations in eight BBS genes by high-resolution homozygosity mapping. J Med Genet 47:262-267

40. Chen J, Smaoui N, Hammer MB, Jiao X, Riazuddin SA, Harper S, Katsanis N, Riazuddin S, Chaabouni H, Berson EL, Hejtmancik JF (2011) Molecular analysis of Bardet-Biedl syndrome families: report of 21 novel mutations in 10 genes. Invest Ophthalmol Vis Sci 52:5317-5324

41. Abu-Safieh L, Al-Anazi S, Al-Abdi L, Hashem M, Alkuraya H, Alamr M, Sirelkhatim MO, Al-Hassnan Z, Alkuraya B, Mohamed JY, et al. (2012) In search of triallelism in Bardet-Biedl syndrome. Eur J Hum Genet 20:420-427

42. Hjortshoj TD, Gronskov K, Philp AR, Nishimura DY, Adeyemo A, Rotimi CN, Sheffield VC, Rosenberg T, Brondum-Nielsen K (2008) Novel mutations in BBS5 highlight the importance of this gene in non-Caucasian Bardet-Biedl syndrome patients. Am J Med Genet A 146A:517-520

43. Feuillan PP, Ng D, Han JC, Sapp JC, Wetsch K, Spaulding E, Zheng YC, Caruso RC, Brooks BP, Johnston JJ, et al. (2011) Patients with Bardet-Biedl syndrome have hyperleptinemia suggestive of leptin resistance. J Clin Endocrinol Metab 96:E528-E535

44. Smaoui N, Chaabouni M, Sergeev W, Kallel H, Li S, Mahfoudh N, Maazoul F, Kammoun H, Gandoura N, Bouaziz A, et al. (2006) Screening of the eight BBS genes in Tunisian families: no evidence of triallelism. Invest Ophthalmol Vis Sci 47:3487-3495

45. Zaghloul NA, Liu Y, Gerdes JM, Gascue C, Oh EC, Leitch CC, Bromberg Y, Binkley J, Leibel RL, Sidow A, et al. (2010) Functional analyses of variants reveal a significant role for dominant negative and common alleles in oligogenic Bardet-Biedl syndrome. Proc Natl Acad Sci U S A 107:10602-10607

46. Sayer JA, Otto EA, OToole JF, Nurnberg G, Kennedy MA, Becker C, Hennies HC, Helou J, Attanasio M, Fausett BV, et al. (2006) The centrosomal protein nephrocystin-6 is mutated in Joubert syndrome and activates transcription factor ATF4. Nat Genet 38:674-681

47. Bachmann-Gagescu R, Phelps IG, Stearns G, Link BA, Brockerhoff SE, Moens CB, Doherty D (2011) The ciliopathy gene cc2d2a controls zebrafish photoreceptor 
outer segment development through a role in Rab8-dependent vesicle trafficking. Hum Mol Genet 20:4041-4055

48. Collin GB, Won J, Hicks WL, Cook SA, Nishina PM, Naggert JK (2012) Meckelin is necessary for photoreceptor intraciliary transport and outer segment morphogenesis. Invest Ophthalmol Vis Sci 53:967-974

49. Adams M, Simms RJ, Abdelhamed Z, Dawe HR, Szymanska K, Logan CV, Wheway G, Pitt E, Gull K, Knowles MA, et al. (2011) A meckelin-filamin A interaction mediates ciliogenesis. Hum Mol Genet:s

50. Hudak LM, Lunt $\mathrm{S}$, Chang $\mathrm{CH}$, Winkler E, Flammer $\mathrm{H}$, Lindsey M, Perkins BD (2010) The intraflagellar transport protein ift80 is essential for photoreceptor survival in a zebrafish model of Jeune asphyxiating thoracic dystrophy. Invest Ophthalmol Vis Sci 51:3792-3799

51. Zhou W, Dai J, Attanasio M, Hildebrandt F (2010) Nephrocystin-3 is required for ciliary function in zebrafish embryos. Am J Physiol Renal Physiol 299: F55-F62

52. Slanchev K, Putz M, Schmitt A, Kramer-Zucker A, Walz G (2011) Nephrocystin-4 is required for pronephric duct-dependent cloaca formation in zebrafish. Hum Mol Genet 20:3119-3128

53. Chaki M, Airik R, Ghosh AK, Giles RH, Chen R, Slaats GG, Wang H, Hurd TW, Zhou W, Cluckey A, et al. (2012) Exome capture reveals ZNF423 and CEP164 mutations, linking renal ciliopathies to DNA damage response signalling. Cell 150:533-548

54. Veleri S, Bishop K, Dalle Nogare DE, English MA, Foskett TJ, Chitnis A, Sood R, Liu P, Swaroop A (2012) Knockdown of Bardet-Biedl syndrome gene BBS9/PTHB1 leads to cilia defects. PLoS One 7:e34389

55. Pretorius PR, Aldahmesh MA, Alkuraya FS, Sheffield VC, Slusarski DC (2011) Functional analysis of BBS3 A89V that results in non-syndromic retinal degeneration. Hum Mol Genet 20:1625-1632

56. Essner JJ, Amack JD, Nyholm MK, Harris EB, Yost HJ (2005) Kupffer's vesicle is a ciliated organ of asymmetry in the zebrafish embryo that initiates left-right development of the brain, heart and gut. Development 132:1247-1260

57. Kramer-Zucker AG, Olale F, Haycraft CJ, Yoder BK, Schier AF, Drummond IA (2005) Cilia-driven fluid flow in the zebrafish pronephros, brain and Kupffer's vesicle is required for normal organogenesis. Development 132:1907-1921

58. Tobin JL, Beales PL (2007) Bardet-Biedl syndrome: beyond the cilium. Pediat Nephrol 22:926-936

59. Harnett JD, Green JS, Cramer BC, Johnson G, Chafe L, McManamon P, Farid NR Pryse-Phillips W, Parfrey PS (1988) The spectrum of renal disease in Laurence-Moon-Biedl syndrome. N Engl J Med 319:615-618

60. Krishnan R, Eley L, Sayer JA (2008) Urinary concentration defects and mechanisms underlying nephronophthisis. Kidney Blood Press Res 31:152-162

61. Bettencourt-Dias M, Hildebrandt F, Pellman D, Woods G, Godinho SA (2011) Centrosomes and cilia in human disease. Trends Genet 27:307-315

10.1186/2046-2530-3-3

Cite this article as: Al-Hamed et al:: Functional modelling of a novel mutation in BBS5. Cilia 2014, 3:3

\section{Submit your next manuscript to BioMed Central and take full advantage of:}

- Convenient online submission

- Thorough peer review

- No space constraints or color figure charges

- Immediate publication on acceptance

- Inclusion in PubMed, CAS, Scopus and Google Scholar

- Research which is freely available for redistribution 